TABLEAU IV

\begin{tabular}{|c|c|c|c|c|c|}
\hline 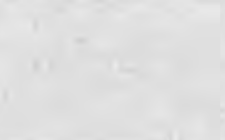 & $\begin{array}{c}\text { Tonine } \\
\text { moyenne } \\
\text { du fil (en } \\
\text { denier) }\end{array}$ & $\begin{array}{l}\text { Résis- } \\
\text { tance } \\
\text { (gr. } \\
\text { denier) }\end{array}$ & $\begin{array}{c}\text { Extensi- } \\
\text { bilité } \\
\text { en } \%\end{array}$ & $\begin{array}{c}\text { Humidité } \\
\text { en } \%\end{array}$ & $\begin{array}{l}\text { Tempé- } \\
\text { rature }\end{array}$ \\
\hline Méthode à CS². & 9,99 & 1,02 & 68,2 & 64 & 22 \\
\hline Méthode à $\mathrm{NH}^{3}$ & 3,51 & 1,88 & 47 & 66 & 20 \\
\hline Lanital italien. & 5,49 & 1,65 & 67 & 67 & 19 \\
\hline Laine naturelle & 4,50 & 2,00 & 39,2 & 66 & 18 \\
\hline
\end{tabular}

La première colonne de ce tableau indique la "tonine " (1) de la fibre obtenue. Ces données indiquent par exemple que la méthode à l'ammoniaque donne une fibre beaucoup plus fine que les fibres italiennes et même plus fine que la fibre naturelle.

La résistance à la traction de la fibre aura une importance très grande. Les échantillons de laine artificielle étudiés ici, dépassent la laine artificielle italienne et se rapprochent davantage de la laine naturelle dont la résistance dépasse la résistance du fil de fer de même épaisseur.

En ce qui concerne les propriétés à l'extension, on constate les mêmes résultats.

Les premiers échantillons obtenus à l'Institut scientifique de la fibre artificielle, par l'ingénieur BARACOFF, atteignant plusieurs dizaines de kilogrammes, ont été envoyés dans des usines textiles pour des essais de toutes sortes.

\title{
MÉTHODE PRATIQUE POUR IMETTRE EN ÉVIDENCE L'ADJONCTION DU LAIT DE VACHE AU LAIT DE CHÈVRE (2)
}

\author{
par le
}

\section{Dr Giovanni MANTOVANI}

De nombreux auteurs (parmi lesquels SteInegger, HeIDUSCHKa et BEYRICH, TEICHERT et STOCKER) se sont occupés de rechercher une méthode apte à mettre en évidence l'adjonction du lait de chèvre au lait de vache. Il ne semble pas, par contre, que le problème de l'adjonction du lait de vache au lait de chèvre ait été jusqu'à présent pris en particulière considération. Il s'agit cependant d'une question de grand intérêt spécialement dans les

(1) Le mot a tonine " est un indica teur de qualité textile de la laine.

(2) L'Igiene Moderna, n० 11, 1936-XV. (Traduction R. LEvIN.) 
régions (comme certaines parties de l'Italie méridionale et des Iles) où le lait de chèvre est abondamment consommé et où sa valeur commerciale est plus élevée que celle du lait de vache.

Laissant de côté les considérations d'ordre économique qui, comme on le sait, sont sujettes à de nombreuses variations, nous montrerons comment la mise en évidence de semblables mélanges est digne de considération en tant qu'elle permet de déceler la vente frauduleuse d'un produit qui n'est pas livré au consommateur tel que celui-ci le demande.

Récemment FicherA a apporté une contribution à la solution du problème. Cet auteur affirme que l'adjonction d'acide tartrique permet d'obtenir un précipité d'aspect divers dans le lait de vache et dans celui de chèvre. En outre, selon Fichera, il serait possible de différencier ces deux laits également d'après la nature du petitlait filtré à travers une toile après précipitation avec l'acide tartrique.

Nous avons cru au contraire plus opportun d'utiliser une réaction enzymatique propre au lait de vache, dont la découverte est due à SchARDINGER. A la fin de 1902, cet auteur avait noté comme le lait de vache, non soumis précédemment au chauffage, avait le pouvoir de décolorer, à une température d'environ $45^{\circ}$, un mélange constitué par $5 \mathrm{~cm}^{3} \mathrm{~d}^{2}$ une solution saturée de bleu de méthylène, $5 \mathrm{~cm}^{3}$ de formaline et 190 d'eau.

De nombreux auteurs se sont occupés ensuite de cette réaction. Nous trouvons un intérêt particulier aux observations de SMIDT (1904), qui montrent que cette réaction n'a pas lieu avec le lait de chèvre.

Pour ce qui concerne son mécanisme, presque tous les savants sont actuellement d'accord pour retenir que la décoloration $\mathrm{du}$ réactif est due à une enzyme spéciale (que récemment SBARSKY et Mrchlin auraient réussi ̀̀ isoler), laquelle aurait le pouvoir de mobiliser les éléments de l'eau et qui, pour cela, a été appelée "perhydridase ". Il s'agirait donc d'un système d'oxydo-réduction dans lequel le bleu de méthylène fonctionnerait comme accepteur de l'hydrogène, tandis que la formaline le serait pour l'oxygène.

Les recherches successives de $\mathrm{BACH}$ ont montré comment la formaline peut être remplacée par d'autres aldéhydes (par exemple l'acétaldéhyde) et aussi par des nitrates qui se voient réduits à des nitrites.

Des recherches très poussées ont été faites ensuite par certains chercheurs pour mettre en évidence l'enzyme dans le lait à divers moments de la lactation et dans les divers composants du lait lui-même. Nous dirons seulement que l'enzyme se montre surtout liée aux globules de graisse. 
Après ces brèves considérations préliminaires, nous passons à l'exposition des résultats de nos essais.

La première fut faite avec le lait total. A $10 \mathrm{~cm}^{3}$ du mélange des deux laits, de chèvre et de vache, en diverses proportions, furent ajoutées 3 gouttes de réactif de Schardinger et, après agitation, l'éprouvette fut mise au bain-marie à $70^{\circ}$, température à laquelle (conformément aux indications de BRAND) la réaction se fait le mieux. Cet essai ne permit d'obtenir des résultats certains que pour les mélanges dans lesquels le lait de vache participait dans la proportion de $50 \%$.

Ensuite, pour rendre la réaction plus sensible, compte tenu que l'enzyme est surtout liée aux globules de graisse, nous a vons cherehé à opérer sur celle-ci, en la séparant par centrifugation. Mais, parce que la masse centrifugée est trop faible, étant donné qu'on opère sur de petites quantités de lait, et aussi parce que cette méthode nécessite l'emploi du centrifugeur, nous avons cru opportun d'abandonner également ce procédé, qui pourtant nous avait donné des résultats nettement meilleurs que le précédent.

Nous avons enfin atteint pleinement le but que nous nous étions fixé en opérant sur des solutions de graisse obtenues en agitant des mélanges de lait avec un dissolvant des graisses. Au besoin peuvent être pris en considération l'éther de pétrole, le benzol, la benzine et l'éther sulfurique. Le dissolvant qui répond le mieux au but est l'éther de pétrole.

Nous avons opéré de la façon suivante:

$10 \mathrm{~cm}^{3} \mathrm{du}$ lait à examiner sont agités dans une éprouvette avec $5 \mathrm{~cm}^{3}$ d'éther de pétrole; on laisse reposer quelques minutes et on pipette $5 \mathrm{~cm}^{3}$ de la solution grasse qui s'est séparée à la surface. A celle-ci, mise dans un tube à essais ordinaire, on ajoute 2 gouttes du réactif de Schardinger. Après agitation, le tube est immergé dans un bain-marie à la température d'environ $40^{\circ}$. On chauffe graduellement jusqu'à $70^{\circ}$ en procédant avec précaution pour éviter une ébullition trop rapide et tumultueuse de l'éther. A $70^{\circ}$, la masse qui contient le lait de vache se décolore en quelques minutes, à condition toutefois que le lait de vache entre dans le mélange dans une proportion non inférieure à $10 \%$. Quand, au contraire, le pourcentage du lait de vache est inférieur à $10 \%$, les résultats sont incertains et cela non pas tant par défaut de réaction, mais parce que la quantité d'enzyme présente peut être si faible qu'elle ne donne pas lieu à décoloration, même si on ajoute une seule goutte de réactif.

De toutes façons, il faut retenir que, en cas de fraude, le pourcentage du lait de vache n'est jamais inférieur à $10 \%$, parce que, dans ce cas, le profit qu'en tirerait le fraudeur serait insignifiant. 
En conséquence, la méthode que nous proposons peut être considérée comme pratique et utile par la simplicité de son exécution et la clarté de la réponse.

\section{BIBLIOGRAPHIE}

BACH. Biochem. Zeitsch., b. 31, 1911, p. 443.

BRAND. Munch. med. Wochenschr., 17, 1907.

Dixon et Thurlow. Biochem. Journal, 18, 1924, p. 971 (Sbarsky et Mrohlin).

FiсневA. Latte, Latticini e conserve alimentari, 12, 1935, p. 159.

Jensen. Zentralb, $f$. Balteriol. $u$. Parasitenk., 18, 1907, p. 211.

KONING. Milchwirtsch. Zentralbl., 3, 1907, p. 41.

Oppenhermer. Zeitsch. $f$. Unters. d. Nahrungs-und Genussmittel, 19, 1910, p, 667.

ReINHARD et SeIBOLD. Biochem. Zeitsch., b. 31, 1911, p. 294; b. 31, 1911, p. 385 .

Roemer. Biochem. Zeitsch., b. 40, 1912, p. 5.

Rullmann. Biochem. Zeitsch., b. 32, 1911, p. 446.

SAMEs. Milchwirtsch, Zentralbl., b. 3, 1907, p. 41.

SASSENHAGEN. Arch. f. Kinderheilkunde, 1910, p. 281.

Sbarsky et Miohlin. Biochem. Zeitsch., b. 155, 1925, p. 485.

SchARDINGER. Zeitsch. f. Unters. d. Nahrungs-u Genusmittel, b. 5, 1902, p. 1113 ; b. 6,1903, p. 865 .

- Chem. Zeitg., b. 28, 1904, p. 704.

SCHERN. Biochem. Zeitsch., b. 19, 1909, p. 261.

Seligmand. Zeitsch. $f$. Hygiene, b. 52, 1905, p. 161 ; b. 58, 1907, p. 1 .

-Zeitsch.f. Angewandte Chem., b. 18, 1906, H. 36.

Sмгот. Hygienische Rundschau, 1904, p. 1137.

- Archiv. F. Hygiene, b. 58, 1906, p. 313.

WEDEMANN. Biochem. Zeitsch., b. 40, 1914, p. 330.

\section{RAPPORT D'UN TRAVAIL D'EXPÉRIIMENTATION SUR LE CONTROLE DE LA MAMIMITE STREPTOCOCCIQUE PAR LA VACCINATION CURATIVE ET PRÉVENTIVE ET QUELQUES IIESURES HYGIÉNIQUES}

par

EDOUARD BROCHU

$$
\text { L. S. A., }
$$

Ass-Professeur de Bactériologie

Institut Agricole d'Oka.
Dr M. PANISSET

M. V., Professeur de Bactériologie et de maladies contagieuses, Ecole de Médecine Vétérinaire de la province de Québec.

Dr M. VEILLEUX

M. V., Professeur de Pathologie Chirurgicale et de Clinique, Ecole de Médecine Vétérinaire de la Province de Québec. (Fin)

D. Traitements de la mammite, autres que la vaccination. Depuis que Nocard et Mollereau ont introduit les irrigations 